REVISTA CHILENA DE LITERATURA

Abril 2010, Número 76, 43 - 70

\title{
TODOS LOS MALES EL MAL. LA "ESTÉTICA DE LA ANIQUILACIÓN" EN LA NARRATIVA DE ROBERTO BOLAÑO ${ }^{1}$
}

\author{
Alexis Candia Cáceres \\ Pontificia Universidad Católica de Chile \\ iacandia@uc.cl
}

\section{RESUMEN / ABSTRACT}

En este artículo se realiza un estudio de las manifestaciones del mal en las novelas de Roberto Bolaño, las que tienen como denominador común la presencia de la aniquilación, es decir, de aquella fuerza que tiende a destruir a los seres humanos. Para esto, se analizan todas las novelas de Roberto Bolaño, desde Consejos de un discípulo de Morrison a un fanático de Joyce (1984) hasta 2666 (2004). Bolaño genera en sus novelas una "Estética de la Aniquilación" que fija las múltiples formas de devastación de mujeres y hombres, lo que lleva a convertir parte importante de sus novelas en un recorrido por la violencia y el horror que ha sacudido a la cultura occidental en el último siglo.

Palabras clave: Roberto Bolaño, novelas, mal, "Estética de la Aniquilación”.

This article proposes the study of the manifestations of evil in Roberto Bolaño's novels, all of which have in common the presence of annihilation, that is, that force which leads to the destruction of human beings. For this purpose, the author analyzes all the novels published by Roberto Bolaño, from Consejos de un discípulo de Morrison a un fanático de Joyce (1984) to 2666 (2004). In his novels Bolaño creates an "Aesthetics of annihilation" which registers the many forms of devastation of women and men; this procedure allows the transformation of a significant portion of his novels in a "tour" of that violence and horror which have shaken Western culture during the last century.

KEY WORDS: Roberto Bolaño, novels, evil, "Aesthetics of annihilation”.

1 Este artículo es parte de mi tesis doctoral titulada “El 'Paraíso Infernal' en la narrativa de Roberto Bolaño". 
Roberto Bolaño asume al mal como la máxima constante de su narrativa. A veces puede aparecer como un tema secundario, como en Los detectives salvajes o, en otros casos, como el eje central sobre el que se articulan sus textos, como acontece en 2666, pero, sea como sea, la iniquidad tiene una poderosa presencia en la narrativa bolañiana. Bolaño aborda sus novelas, por lo general, desde las perspectivas de los investigadores o de los testigos que reconstruyen los asesinatos y no desde la mirada de los victimarios. De esta forma, deja en el misterio las razones que mueven al mal en su narrativa. Así, es clave hacer un esfuerzo por penetrar en los intersticios de sus textos a fin de encontrar los motivos que existen detrás de una fuerza primigenia que tiene un rol crucial en sus novelas. De ahí que el mal sea el tema absoluto de La literatura nazi en América, Estrella distante, Nocturno de Chile y 2666, textos que conforman su tetralogía del mal.

Hay numerosos críticos que han notado la importancia del mal en la narrativa de Roberto Bolaño. Los aportes de Espinosa, Manzoni y González ${ }^{2}$ son valiosos en este sentido, debido a que subrayan la relevancia de la temática más poderosa de las novelas de Bolaño. Ahora bien, me interesa profundizar el análisis de la función del mal en sus novelas, determinando sus alcances, sus límites y su sentido -si es que lo hay-y, sobre todo, establecer cómo el mal

2 Patricia Espinosa habla de la estética de la desaparición y del mal que es posible apreciar en Consejos de un discípulo de Morrison a un fanático de Joyce y del entrecruce de proyecto artístico con lo perverso en Estrella distante y La literatura nazi en América en el "Estudio preliminar" que incluye en el libro Territorios en fuga. Estudios críticos sobre la obra de Roberto Bolaño. Celina Manzoni concentra su mirada en lo siniestro que cruza a $L a$ literatura nazi en América, novela marcada por una fascinación por lo perverso, "[...] por la necesidad casi compulsiva, de poner en movimiento lo oscuro, lo tenebroso" (Manzoni, "Biografías mínimas/ínfimas" 27). Daniuska González lleva sus conclusiones un poco más allá y afirma que el mal es el tema absoluto de Bolaño: "Escribir el mal, o mejor, convertir la propia escritura en mal; sino y signo de la narrativa de Bolaño [...] La oscuridad del silencio, el desasosiego, el asesinato, palabras bajo la sombra de un mal absoluto y humano. Acaso como el nuevo manuscrito del ya viejo y conocido Satán” (González 31). 
dialoga con la "Magia" 3 para formar una estructura que, en mi perspectiva, permite explicar la producción literaria bolañiana: el "Paraíso Infernal"4.

Hablar del mal es ingresar al centro de gravedad de la literatura. Si la literatura es lo esencial o no es nada, como piensa Bataille, pocos elementos pueden situarse tan bien en el núcleo literario como la maldad. Más aún al tomar en cuenta que el mal puede considerarse como el motor secreto que ha movido, en innumerables ocasiones, los andamiajes de la humanidad. Por lo demás, es tal la relevancia del mal en la literatura occidental, que autores tan disímiles como Dante Alighieri, Charles Baudelaire, Lautréamont, William Blake, Marqués de Sade, Franz Kafka y Jean Genet, han dedicado innumerables páginas a dar luces sobre la parte maldita.

Para resolver la manera en que Bolaño desarrolla el mal en sus novelas, resulta importante la tesis que adopta Benard Sichère en Historias del mal. Establece que cada época inventa sus propios protocolos para afrontar y a la vez exorcizar el mal. Pese a que la experiencia de la perversión depende de los códigos de una cultura determinada, Sichère cree que existe una invariable que cruza tiempo y espacio, esto es lo que él denomina el enigma mismo, "[...] la evidencia de algo extraño y amenazador que el sujeto experimenta y que desde el interior lo quebranta hasta el punto de arrancarlo de su propia

3 Lejos de las definiciones tradicionales de lo mágico, Bolaño considera a la magia como aquellos elementos fascinantes que rompen con la lógica consumista de las sociedades contemporáneas. Bolaño piensa que ante sociedades regidas por la oferta y la demanda, es necesario introducir una pieza que evite la enajenación a la que conduce el capitalismo. De ahí que emplee la magia para expandir la experiencia humana allende de los límites del mercado: "La vida es demanda y oferta, u oferta y demanda, todo se limita a eso, pero así no se puede vivir. Es necesaria una tercera pata para que la mesa no se desplome en los basurales de la historia, que a su vez se está desplomando permanentemente en los basurales del vacío. Así, que toma nota. Ésta es la ecuación perfecta: oferta + demanda + magia. ¿Y que es magia? Magia es épica y también es sexo, y bruma dionisiaca y juego" (Bolaño, 2666 291).

4 El "Paraíso Infernal" de la narrativa de Roberto Bolaño está compuesto por dos constantes que parecen regir sus novelas; en primer término, por el espejeo de la oscuridad del alma humana (mal) y, en segundo lugar, por la exploración de los aspectos mágicos de la existencia (sexo, épica, juego y bruma dionisíaca). De esta forma, las letras bolañianas están fundadas sobre un contrapunto entre la "magia" y el mal. Bajo esta perspectiva, es posible sostener que la obra de Bolaño puede considerarse como un "Paraíso Infernal", esto es, como un espacio literario en que conviven los elementos más sórdidos con los más "mágicos" del hombre. En suma, los libros de Bolaño podrían sintetizarse como un oasis de magia en medio de un desierto de maldad, parafraseando el verso de Charles Baudelaire que sirve de epígrafe en 2666. 
cohesión" (Sichère 19). Los postulados de Sichère son claves para explicar la función del mal en la narrativa de Bolaño, debido a que el autor de 2666 adopta parte importante de su línea reflexiva. Sin embargo, no se puede soslayar que su novelística se resiste a ser analizada por otros conceptos propuestos por el teórico francés. Pues bien, es clave desglosar las convergencias y las divergencias de Bolaño con Sichère.

Las novelas de Bolaño no se concentran en afrontar y exorcizar el mal de una cultura y una época determinada, no excluyen esos patrones, por cierto, pero sus textos son más bien una amplia exploración de las múltiples facetas que adopta la maldad en la civilización occidental ${ }^{5}$. De ahí que en sus novelas

5 Pese a la amplia mirada espacio-temporal del mal presente en las novelas de Bolaño, no se pueden soslayar las condiciones de producción y recepción de su obra, las que, en mi perspectiva, están marcadas por la presencia de la globalización, de la postmodernidad y del silenciamiento de las utopías. Para José Joaquín Brunner, la globalización es un fenómeno político, económico y cultural que se expresa a través de cuatro elementos: (1) La universalización de los mercados y el avance del capitalismo postindustrial; (2) la difusión del modelo democrático como forma ideal de la organización de la polis; (3) la revolución de las comunicaciones que lleva a la construcción de la sociedad de la información; (4) la creación de un clima cultural llamado posmodernidad (Brunner 14). De estos cuatro factores, la expansión del capitalismo es uno de los elementos más relevantes para estudiar la narrativa de Roberto Bolaño, dado que sus textos cuestionan la lógica oferta-demanda que, en gran medida, determina las relaciones del mundo contemporáneo. Así, Bolaño critica en sus textos a un capitalismo que se ha extendido sin límites hasta los confines del planeta, envolviéndolo en la lógica de los mercados y las redes de información. Por otra parte, resulta interesante el clima cultural mencionado por Brunner, la postmodernidad, fenómeno que tiene una enorme cantidad de interpretaciones pero que, dados los alcances del proyecto escritural de Bolaño, opto por mirarla a partir de las propuestas de Lyotard y Lechner. Lyotard sostiene que la condición postmoderna está marcada por la incredulidad respecto de los metarrelatos, tales como la filosofía y la historia. Lechner concuerda con Lyotard en tanto sostiene que la postmodernidad es, sobre todo, la desconfianza hacia los metadiscursos que buscan la totalidad. De esta forma, la crítica postmoderna persigue la relativización de todas las normas, considerando la voluntad de poder como la verdadera fuerza estructuradora del magma de diferencias sociales. Bajo está lógica, la utopía - proyección humana de un mundo idealizado- cae progresivamente en un amplio descrédito e incluso en un silenciamiento. Roberto Bolaño asume el fin de la utopía que representan los procesos políticos encabezados por la izquierda latinoamericana en la segunda parte del siglo XX, los que apuntan a la construcción de una sociedad justa e igualitaria. Bolaño elige en su juventud la ruta revolucionaria, es decir, una causa políticosocial que implica la creación de una comunidad igualitaria y que, en su perspectiva, sólo podía construirse en el Chile de Salvador Allende. De ahí el largo viaje que Bolaño realiza a Chile a mediados de 1973. Sin embargo, el trayecto queda marcado por el fracaso. La utopía se disuelve ante sus propios ojos. Así, el fin del gobierno de la unidad popular marca el fin de sus concepciones utópicas y el encuentro con una realidad brutal: "Chile cumple, por 
sea posible apreciar la ferocidad sádica, la trasgresión, la barbarie colectiva extrema, entre otras manifestaciones de la maldad. Lo anterior tiene que ver con la concepción que Bolaño maneja respecto de lo que es una escritura de calidad: "[...] saber meter la cabeza en lo oscuro, saber saltar al vacío, saber que la literatura básicamente es un oficio peligroso" (Bolaño, Entre paréntesis 36). Una propuesta literaria tendiente a penetrar en los recovecos sombríos del ser humano acaba, inevitablemente, encontrándose con todos los rostros de la maldad. De cierta forma, esto se relaciona con la diferencia que Bolaño traza entre el bien y el mal: "El mal es básicamente el egoísmo narrado de diferentes formas. La frontera la delimita la mirada que tengas sobre el otro, el saber que el otro existe" (Braithwaite 81). Precisamente Bolaño narra las múltiples formas que adquiere ese egoísmo ${ }^{6}$.

Con todo, hay una importante convergencia entre Sichère y Bolaño. La narrativa de Bolaño adopta la presencia de la invariable del mal. Muchas son las formas de narrar el mal en los textos de Bolaño, pero todos los crímenes no hablan sino de esa fuerza que cruza tiempo y espacio y que quiebra al sujeto hasta sacarlo de su propia cohesión. Ahora bien, no basta con mencionar la presencia de esa invariable sino que es necesario precisar en qué consiste esa fuerza. Bolaño asocia el mal con la destrucción, es decir, que el mal es pensar que: " $[\ldots]$ el otro no existe, no piensa, no siente, y hacerle daño. O saber que existe, piensa y siente, y hacerle daño. Destruir dentro de uno mismo, consciente o inconscientemente, toda atadura moral y ética. Creer

supuesto, una triste función bisagra. Según las reglas que ordenan el universo narrativo de Roberto Bolaño, es en Chile donde se juega y se pierde la última carta. En Chile culmina y se va al diablo la opción revolucionaria que Fidel, el Ché y los demás pusieron en marcha a fines de los años cincuenta desde los faldeos de Sierra Maestra" (Rojo, "Bolaño y Chile" 208209). Cabe destacar, en esta línea, que el silenciamiento de la utopía es un hito que establece, a su vez, el surgimiento de una de las fuentes del mal en la narrativa de Roberto Bolaño, la dictadura militar chilena, experiencia histórica abordada por Bolaño en parte importante de su narrativa y, especialmente, en Estrella distante y Nocturno de Chile.

6 Pese a la amplia gama de tonos que emplea Bolaño para retratar el mal, existe un límite que es necesario consignar, esto es, que lo malévolo se desarrolla en el interior de la esfera de la subjetividad. Bajo esta perspectiva, sus novelas solo se pueden entender a la luz del trabajo de Sade, debido a que los textos sadianos son los que marcan la irrupción de un mal radical entendido como lo impensado de la razón moderna y, en consecuencia, establecen el fin de la influencia de la divinidad -sobre todo del dios cristiano- en la concepción de la perversión en Occidente, "[...] el mal decididamente ha cambiado de régimen; ahora surge a una extraña luz de fin de mundo, en un cielo que han abandonado Dios y las figuras paternales" (Sichère 164). 
que todo vale" (González 28). Todas las formas de contar la iniquidad en su narrativa tienen como común denominador la presencia de la destrucción. Bolaño genera novelas que retratan distintas maneras de demoler a hombres y mujeres y, en este sentido, se puede hablar de una estética que intenta fijar las diversas formas que adopta la destrucción.

¿Existe una estética de la destrucción en la narrativa de Roberto Bolaño? Hasta cierto punto. El problema de emplear ese concepto es que Aldo Pellegrini define la estética de la destrucción sobre la base de una serie de conceptos que no se adaptan del todo a la narrativa de Bolaño. Sin embargo, sus aportes abren un sendero que puede ser explotado para analizar el mal en sus novelas. En "Fundamentos para una Estética de la Destrucción", Pellegrini establece un estrecho diálogo entre destrucción y creación en los ciclos de la naturaleza ${ }^{7}$. Pellegrini sostiene que la destrucción de la naturaleza tiene un sentido creador. Los peores cataclismos responden a necesidades de la naturaleza misma, aunque estén en pugna con las necesidades del hombre. Con relación a la destrucción manejada por el hombre, según Pellegrini, aparecen dos elementos que la naturaleza ignora: la destrucción sin sentido y la destrucción por el odio.

Pellegrini busca dignificar el concepto de destrucción, uniéndolo a la creación: "Destrucción y construcción constituyen para ella dos fases del mismo proceso. $\mathrm{Y}$ en efecto [...] crear es en definitiva transformar, es decir, destruir algo para hacer con ese algo una cosa nueva" (Pellegrini $s / n$ ). De esta forma, Pellegrini piensa que el artista tiene que emplear a la destrucción como un fermento creador: "Ya es tiempo de que el artista dé las verdaderas normas de la destrucción, puesto que el acto de destruir es inseparable del hombre. Cuando la destrucción es voluntaria y desinteresada cumple primordialmente una función estética" (Pellegrini s/n). Si los postulados de Pellegrini se detuvieran en este punto, podrían ser útiles para abordar las novelas de Bolaño. A todas luces, es posible un análisis a partir de las nociones de la destrucción sin sentido y la destrucción por el odio en 2666. También es dable apreciar en la lógica torcida de Carlos Wieder la imbricación de construcción y destrucción en el proceso creador.

7 Para Pellegrini existe una corriente de destrucción que circula por la naturaleza " [...] que nos rodea, y toda esa tarea de destrucción confluye en la construcción de la vida. Y esa misma corriente de destrucción circula por el interior de la vida concediéndole a esta su fuerza y su fragilidad, y esa magnífica calidad propia de lo efímero. Todo cambio implica destrucción, y la naturaleza es esencialmente cambio" (Pellegrini $\mathrm{s} / \mathrm{n}$ ). 
Los problemas de los postulados de Pellegrini para abordar la narrativa de Bolaño pasan, en primer término, porque este considera que la destrucción del artista no es el acto brutal y sin sentido que determina el odio sino que es un acto que tiene sentido y este sentido lleva la marca indeleble del humor. Pellegrini habla del humor como un fenómeno destructor de la más alta categoría que ataca lo estúpido y lo rutinario. Nadie podría desconocer la importancia del humor en las novelas de Bolaño, incluso en los momentos más duros existe una cuota de humor que permite purgar el horror, sin embargo, no es posible sostener que "La parte de los crímenes" de 2666 tenga un sentido y que este lleve el sello del humor. Por el contrario, "La parte de los crímenes" es la suma de numerosos actos brutales movidos por el odio o el sin sentido. Parafraseando a Gertrude Stein, es dable sostener que una mujer desmembrada no es la belleza. Una mujer desmembrada no es el humor. No es el misterio del mundo. Una mujer desmembrada es una mujer desmembrada.

Pellegrini sostiene que el impulso que mueve al hombre hacia la destrucción tiene un sentido y toca al artista revelarlo: "Cualquiera que sea la motivación del acto destructivo: el furor, el aburrimiento, la repugnancia por el objeto, la protesta, ese acto debe tener un sentido estético y ese sentido evita que la destrucción [...] se transforme en aniquilamiento" (Pellegrini $\mathrm{s} / \mathrm{n}$ ). Además, establece que destrucción y aniquilamiento son términos antagónicos desde el punto de vista del artista. La destrucción de un objeto no lo aniquila, nos enfrenta con una nueva realidad del objeto, la carga de un sentido que antes no tenía. Aquí está la clave del aporte de Pellegrini para abordar el mal en las novelas de Bolaño. Analicemos sus alcances. Parto con una cita a Bolaño: "La muerta tenía diez años, aproximadamente [...] En el cuerpo se apreciaron ocho heridas de cuchillo, tres a la altura del corazón. Uno de los policías se puso a llorar cuando la vio" (Bolaño, 2666 627). ¿Cuál es el sentido de ese episodio? Tal vez el sin sentido. Desde luego el horror. ¿Cuál es el acto procreador que le da sentido a esa destrucción? Ninguno. Solo hay una niña asesinada. Es un acto estéril. ¿Dónde radica la belleza del homicidio? No hay belleza. Solo aniquilación. En suma, me parece que en la narrativa de Bolaño no existe una estética de la destrucción, no, al menos, en los términos que lo plantea Pellegrini. Sin embargo, Pellegrini opone la destrucción a la aniquilación y, en esta línea, creo que sí existe un terreno fértil para trabajar el mal en las novelas de Bolaño. Pellegrini cierra su texto de la siguiente forma: "La destrucción depurada por el artista [...] nos revelará inéditos mecanismos de belleza, oponiendo así su destrucción 
estética a esa orgía de aniquilamiento en que está sumergido el mundo de hoy" (Pellegrini s/n). Las novelas de Bolaño intentan mostrar esa orgía de aniquilamiento en la que ha estado sumergido Occidente desde hace muchos años, esa es la invariable del mal con la que está dialogando la narrativa bolañiana, la fuerza que pretende arruinar o incluso reducir a la nada a los personajes que habitan en sus libros.

En Sobre la historia natural de la destrucción, W. G. Sebald incluye una reflexión de Solly Zuckerman sobre la actuación de sir Arthur Harris, militar responsable de la destrucción de varias ciudades alemanas en la Segunda Guerra Mundial: “[...] creía en la destrucción por la destrucción y por ello representaba inmejorablemente el principio más íntimo de toda guerra, es decir, la aniquilación más completa posible del enemigo, con todas sus propiedades, su historia y su entorno natural" (Sebald 28). Cuando Bolaño aborda los asesinatos de judíos en la Segunda Guerra Mundial, los crímenes de la dictadura militar chilena o la historia de las mujeres asesinadas en Santa Teresa no está sino plasmando esa "Estética de la Aniquilación" que tiene que ver con poner en escena las múltiples formas de destruir totalmente al otro, estableciendo como el horror y la violencia son parte del engranaje que ha movido, en cierta medida, la historia occidental durante los últimos siglos. Bolaño produce una "Estética de la Aniquilación" que está compuesta por un recorrido por terrenos estériles que adolecen de falta de belleza o humor y en donde la devastación es el sino que mueve a numerosos personajes. No siempre la aniquilación será total en las novelas de Bolaño, sin embargo, cada vez que se pongan en marcha los mecanismos de la "Estética de la Aniquilación" hombres y mujeres padecerán la fuerza de quienes trazan los senderos del mal.

\section{FILOSOFÍA DEL TORTURADOR}

La "Estética de la Aniquilación" tiene su primera parada en una de las tendencias más duras de la narrativa de Bolaño: la ferocidad sádica. El Marqués de Sade no es un esteta más del mal, por el contrario, es el máximo representante de la perversión: "El sadismo es el Mal: si se mata por una ventaja material, no estamos ante el verdadero Mal; el Mal puro es cuando el asesino, además de la ventaja material, goza por haber matado" (Bataille 11). Bataille identifica esa voluptuosidad como el frenesí sádico que consiste en enumerar hasta el agotamiento las posibilidades de destruir a los seres 
humanos, de destruirlos y gozar con el pensamiento de su muerte y de su sufrimiento. Bernard Sichère establece, por su parte, que en Sade "[...] se percibe una especie de obsesión por la purificación feroz y el impulso de agotar todas las figuras de la violencia, violencia que incluye en sus puestas en escena soñadas más o menos todas las prácticas de castigo y de suplicio conocidas hasta entonces en la historia de los hombres" (168).

2666 es la novela que explora con mayor fuerza, actualmente, el frenesí sádico, sobre todo, en "La parte de los crímenes", texto que narra los asesinatos de mujeres en la ciudad de Santa Teresa, México, trasunto de Ciudad Juárez $z^{8}$. Pese a que 2666 no muestra la brutalidad de Las 120 jornadas de Sodoma, hay una serie de elementos similares a la forma de operar de Sade. 2666 enumera múltiples formas de aniquilar el cuerpo femenino. En primer término, las mujeres no solo son asesinadas a través del estrangulamiento, ultimadas por armas blancas o de fuego sino que, al menos la tercera parte de ellas, padecen múltiples vejaciones sexuales que aun incluyen la tortura:

El siete de octubre fue hallado a treinta metros de las vías del tren [...] el cuerpo de una mujer de edad comprendida entre los catorce y los diecisiete años. El cuerpo presentaba señales claras de tortura, con múltiples hematomas en brazos, tórax y piernas, así como heridas punzantes de arma blanca [...] ninguna de las cuales, sin embargo, penetró algún órgano vital [...] Según el forense la causa de la muerte fue estrangulamiento. El pezón del pecho izquierdo presentaba señales de mordeduras y estaba medio arrancado, sosteniéndose tan sólo en algunos cartílagos (724).

En segundo término, los crímenes no están determinados por intereses económicos. No hay un intento de extorsión ni de tráfico de órganos ni mucho menos de robo, como sucede, por ejemplo, con una niña que no puede ser identificada:

A finales de septiembre fue encontrado el cuerpo de una niña de trece años, en la cara oriental del cerro Estrella [...] su pecho derecho

\footnotetext{
8 A fin de situar el papel que juega Santa Teresa en la narrativa bolañiana es clave tener en cuenta que Bolaño considera a Ciudad Juárez como el infierno. Cuándo Mónica Maristain le pregunta cómo es el infierno, Bolaño responde: "Como Ciudad Juárez, que es nuestra maldición y nuestro espejo, el espejo desasosegado de nuestras frustraciones y de nuestra infame interpretación de la libertad y de nuestros deseos" (Bolaño, Entre paréntesis 339).
} 
había sido amputado y el pezón de su pecho izquierdo arrancado a mordidas. Vestía pantalón de mezclilla de marca Lee, de buena calidad, una sudadera y un chaleco rojo. Era muy delgada. Había sido violada repetidas veces y acuchillada y la causa de la muerte era rotura del hueso hioides (584).

En tercer término, la voluptuosidad de los criminales radica en el modus operandi: las mujeres son secuestradas, ultrajadas durante días $\mathrm{y}$, luego, eliminadas. Por lo general, son asesinadas en un lugar y luego son llevadas a sitios poco frecuentados. Lo anterior evidencia que los criminales disfrutan del martirio de sus víctimas, quienes responden a un determinado patrón: muchachas jóvenes, de pelo negro y largo, delgadas, pertenecientes a los estratos socioeconómicos bajos:

En el caso de Mónica Posadas, ésta no sólo había sido violada 'por los tres conductos' sino que también había sido estrangulada. El cuerpo, que hallaron semioculto detrás de unas cajas de cartón, estaba desnudo de la cintura para abajo [...] La vagina estaba desgarrada. La vulva y las ingles presentaban señales claras de mordidas y desgarraduras, como si un perro callejero se las hubiera intentado comer (577).

Bajo este prisma, es interesante el diagnóstico del investigador Albert Kessler en 2666, el que realiza un parangón entre el impacto mediático que provocó el acuchillamiento de una mujer francesa y el escaso interés por los homicidios de miles de personas durante la comuna de París. Para Kessler, la francesa pertenece a la sociedad y, por ende, su muerte es legible; por el contrario, los comuneros no son parte de la comunidad y, en consecuencia, sus muertes no tienen relevancia pública. Las mujeres de Santa Teresa pertenecen a este último grupo. De ahí que Kessler afirme:

Compartiré contigo tres certezas. A: Esa sociedad está fuera de la sociedad, todos, absolutamente todos son como los antiguos cristianos en el circo. B: Los crímenes tienen firmas diferentes. C: Esa ciudad parece pujante, parece progresar, de alguna manera, pero lo mejor que podrían hacer es salir una noche al desierto y cruzar la frontera, todos sin excepción, todos (Bolaño, 2666 339).

Ahora bien, el trabajo de Sade apunta, en último término, a la negación en el más amplio y profundo sentido. Gilles Deleuze distingue entre dos niveles de negación. La negación como un proceso parcial y la negación pura como 
una idea totalizante. Lo anterior, permite distinguir entre dos naturalezas: secundaria y primaria. La naturaleza secundaria está limitada por sus propias reglas y leyes. La negación se extiende por este tipo de naturaleza, pero es incapaz de alcanzar su totalidad. Así, la destrucción no es nada más que el reverso de la creación y el cambio. La negación es penetrante, sin embargo, su acción es parcial. De ahí el desacuerdo del sádico ante una naturaleza que parece negar la posibilidad del crimen perfecto. Aunque el pensamiento del dolor de los otros le produce placer no se siente cómodo, puesto que el sádico desea nada menos que la negación que puede ser considerada como el reverso de lo positivo, es decir, una idea absoluta.

En oposición a lo anterior encontramos la naturaleza primaria y la negación pura que anula todos los reinos y todas las leyes, libre para la necesidad de crear, preservar o individualizar. La negación pura no necesita una fundación y está más allá de toda fundación, “[...] un delirio primario, un original y eterno caos exclusivamente compuesto de salvajes y lacerantes moléculas" (Deleuze 27, traducción propia). Desde luego, el sádico es incapaz de alcanzar esa negación pura. De ahí su rabia y desesperación cuando se da cuenta de la insignificancia de sus crímenes en relación con la idea que él sólo puede alcanzar a través del pensamiento: el libertino sueña lo universal e impersonal o, como dice Clairwil, un crimen que es perpetuamente efectivo.

Sade se cuestiona bajo qué condiciones un dolor producido en la naturaleza secundaria puede proyectarse hacia la naturaleza primaria. Esta es la pista del significado de las repeticiones en los textos de Sade. Así, el libertino no puede hacer más que acelerar y condensar el movimiento de su violencia, consiguiendo la aceleración mediante la multiplicación de sus víctimas. La condensación implica que la violencia no debe disiparse bajo la influencia de la inspiración, del impulso o del placer. La ferocidad sádica debe ejercitarse a sangre fría y concentrarse a través de la razón demostrativa.

Los asesinos de 2666 tienen en común con los sádicos el deseo de acelerar y multiplicar la violencia. Por eso hay un intento constante por elevar el número de víctimas, el que, en definitiva, se empina hasta las 109 mujeres asesinadas. Aun cuando los homicidios tienen firmas diferentes, es dable sostener que existen varios asesinos que tienden a buscar la negación pura. De esta forma, hay una constante que se repite en la novela. La fórmula es la siguiente: violación + tortura + estrangulamiento. La reiteración del procedimiento evidencia la crueldad de los perpetradores. En este sentido, me interesa destacar las analogías de las muertes de Andrea Pacheco y Emilia Escalante: 
A mediados del mes de noviembre Andrea Pacheco Martínez, de trece años, fue raptada al salir de la escuela secundaria [...] Cuando la encontraron, dos días después, su cuerpo mostraba señales inequívocas de muerte por estrangulamiento, con rotura del hueso hioides. Había sido violada anal y vaginalmente. Las muñecas presentaban tumefacciones típicas de ataduras (Bolaño, 2666 490).

Dos días después de aparecer el cuerpo de la primera víctima de agosto fue encontrado el cuerpo de Emilia Escalante Sanjuán, de treintaitrés años, con profusión de hematomas en el tórax y el cuello [...] El informe del forense dictamina que la causa de la muerte es estrangulamiento, después de haber sido violada innumerables veces (Bolaño, 2666 576).

Deleuze sostiene que la función descriptiva está subordinada a la función demostrativa en los textos de Sade. Para éste, es capital pasar de la teoría a la práctica ${ }^{9}$. Las descripciones deben ser precisas y abordar dos áreas: las acciones crueles y las desagradables. Ambas son placenteras para los libertinos. 2666 se sitúa en esos parámetros. La muerte de Jazmín Torres constituye un poderoso signo en esta línea:

Cuatro días después del hallazgo del cadáver de la niña Guadalupe Guzmán Prieto se encontró en el cerro Estrella [...] el cuerpo de Jazmín Torres Dorantes, también de once años de edad. Como causa de la muerte se dictaminó un shock hipervolémico producido por las más de quince puñaladas que le asestó su agresor o agresores. El frontis vaginal y anal determinó que había sido violada repetidas veces (Bolaño, 2666 682).

Bolaño parece ensombrecer el horror de Santa Teresa a la luz de las pesadillas de Sade, demostrando que el razonamiento de los asesinos es una forma de violencia y que ellos están del lado de la violencia. Los criminales de 2666, como los perpetradores sadianos, entienden la relación con sus víctimas solo a partir de la posesión y, en consecuencia, la víctima no es nada más que

9120 jornadas de Sodoma constituye un excelente ejemplo de la relación de teoría y práctica en Sade. Basta recordar que las orgías se encontraban precedidas por las narraciones de las cuatro historiadoras, las que no solo instruían y entretenían a los cuatro libertinos sino que excitaban sus sentidos y abrían su imaginación para los cuadros que habrían de poner en marcha hacia el fin del día. 
un objeto de placer y/o destrucción. Así, la ferocidad sádica pone en escena diversas formas de devastar a las mujeres de Santa Teresa, plasmando una de las facetas más oscuras de la "Estética de la Aniquilación".

\section{ASESINOS POR NATURALEZA}

Consejos de un discípulo de Morrison a un fanático de Joyce cuenta la serie de crímenes efectuados por Ana Ríos y Ángel Ros. Mientras Ros es un escritor fracasado que pervive tocando el bajo en una banda tropical, Ana es una delincuente sudamericana que posee marcados instintos asesinos. De hecho es Ana quien insta a Ángel a iniciar una aventura en el crimen: "Pensé entonces que puestos a morir quizá mejor sería sufrirlo en movimiento y no enfermo o viejo en una cama" (Bolaño, Consejos 16). El trayecto de los violentos amantes evoca las propuestas de Jean Baudrillard en La transparencia del mal: ensayo sobre los fenómenos extremos. Baudrillard piensa que el principio del mal es la energía de la parte maldita. Así, el mal no es el principio de la muerte sino el principio vital de la desunión y la violencia infligida a la razón. Baudrillard tiende a reconocer la vitalidad de una violencia que lleva las cosas más allá de sus propios fines. En este sentido, el mal es una fuerza que libera las costumbres, las leyes y los placeres, conduciendo, en definitiva, a la trasgresión y al crimen.

Consejos de un discípulo de Morrison a un fanático de Joyce se mueve a través de la violencia de la parte maldita. Ana y Ángel se sumen en una fiesta de estupefacientes, sexo duro y violencia. Aunque el motivo criminal primario de Ana y Ángel tenía que ver con obtener recursos económicos, el brutal asesinato de una anciana a manos de Ana detona un periplo brutal que tiene al robo, a la violación y al homicidio como las principales paradas de un ardiente verano en Barcelona. Tal vez la escena de Consejos que en mayor medida ilustra la transgresión de Ríos y Ros es el asalto al subgerente de una empresa catalana, a su mujer y a su empleada:

- Tírate a la filipina.

- Las cosas que se te ocurren, vámonos.

- Tíratela [...] Tiene dieciocho y es más puta que una gallina [...] Estoy caliente, Ángel, míralos. [...]

- Pero si no puedo, no hay contexto, ¿lo entiendes tú?

- No, no, si vamos a cagar pronto, te das cuenta, es como un regalo, tírate a la rubia si quieres, está buena... (49) 
El curso de acción de Ángel y Ana está acorde a la energía del mal que los lleva a cruzar los límites de la crueldad. El asalto acaba acorde a las premisas de Baudrillard. De hecho, luego de abusar de la mujer del subgerente, Ros sale a buscar a Ana y encuentra una habitación de pesadilla:

Sobre una alfombra [...] yacía el cuerpo de la filipina, boca abajo y con las piernas separadas. El subgerente estaba en la cama, de cara a la pared; un hilo de sangre coagulada se le dibujaba desde la nuca hasta el omóplato. Ambos estaban desnudos, aunque sus desnudeces eran de signo distinto: desesperada la de la muchacha, tristísima; y estúpidamente serena la del hombre. Ambos estaban muertos (55).

Los crímenes de Ana y Ángel parecen movidos por el sinsentido. Un sinsentido motivado por el exceso de estimulantes -drogas y alcohol-que consumen los amantes. El contacto con la muerte parece contagiarlos con un deseo enorme de violencia y destrucción similar al trayecto que siguen Mickey Knox y Mallory Wilson Knox en la cinta Natural Born Killers (1994) de Oliver Stone. Tanto la pareja de Bolaño como la de Stone fijan diversas formas de aniquilación en un viaje veloz y brutal por Cataluña y diversas ciudades de Estados Unidos, respectivamente, poniendo en escena, a la postre, una "Estética de la Aniquilación" que lleva la violencia urbana hasta el extremo.

\section{APOCALIPSIS AHORA}

2666, La literatura nazi en América, Estrella distante y Nocturno de Chile adoptan una serie de claves propias de la barbarie colectiva extrema. Mientras la primera retoma los horrores de la empresa nazi, las otras la abordan la 'demonización' política que divide a la sociedad chilena en hombres y "humanoides" 10 . La barbarie colectiva extrema es una de las contribuciones al enigma de la iniquidad de la cultura occidental en el siglo XX. Sichère

10 El almirante José Toribio Merino, integrante de la Junta de Gobierno que encabezó Chile entre 1973 y 1990, calificó como "humanoides" a los miembros del Partido Comunista en 1986, "En Chile y en todo el mundo hay dos tipos de seres: los humanos y los humanoides. Los humanos somos nosotros. Los humanoides pertenecen al Partido Comunista". En http:// www.lun.com/ElDia/detalle_noticia.asp?cuerpo $=701 \&$ seccion $=801 \&$ subseccion $=901 \&$ idn oticia=V4C04PQ20060307 
sostiene que su mayor ejemplo es el nazismo, el que en los límites de la política despliega una furia destructora que pone en tela de juicio la idea misma del hombre y el que en los límites del pensamiento exhibe un momento del horror radical más allá de todos los sistemas de valores instituidos como un desafío a todo discurso que pretenda dominar lo imposible. Sichère piensa que si las situaciones extremas nos invitan a concebir al sujeto humano como subjetivación de un cuerpo y que ese cuerpo era definido a priori como humanizable más allá de toda reducción al ente biológico, la empresa nazi apunta precisamente a devastar esa subjetivación: la destrucción del pueblo judío implica la degradación sistemática del ser humano. Para Maltroux, el horror de la barbarie colectiva conduce al infierno, "[...] el infierno no es el horror, el infierno es verse envilecido hasta la muerte, ya sea que la muerte llegue, ya sea que pase: la espantosa abyección de la víctima, la misteriosa abyección de verdugo" (Sichère 205).

Bolaño narra algunos momentos de la Segunda Guerra Mundial en "La parte de Archimboldi" de 2666, centrando su mirada en los movimientos de una división del ejército alemán que se desplaza hacia el este de Europa. Bolaño sigue el trayecto del grupo que integra Hans Reiter. Los desplazamientos de Reiter le permiten tratar el destino de algunos judíos en Polonia a manos del funcionario nazi Leo Sammer. La actuación de Sammer se enmarca dentro de la "solución final" "11 diseñada por Hitler y responde a la banalidad de mal desarrollada por Hannah Arendt en Eichmann en Jerusalén, Un estudio sobre la banalidad del mal.

El concepto introducido por Arendt no apunta a establecer la intrascendencia de la maldad. Arendt emplea la banalidad del mal pare referirse a las características sicológicas de Eichmann, quien, lejos de la profunda inteligencia y del bagaje filosófico-cultural de los asesinos de Sade ${ }^{12}$, tiene una personalidad común y vulgar que no le impide, sin embargo, poner en marcha parte de la maquinaria de destrucción nacional socialista. Arendt

11 La "solución final" es la política sistemática de exterminio de los judíos impuesta por el régimen nazi en 1942. Para esto, se emplearon dos métodos: los campos de concentración -Auschwitz fue el más importante de ellos-y las fuerzas de las SS que actuaban detrás de los cuerpos del ejército alemán.

12 Pienso en el voluptuoso y libertino Dolmancé de Filosofía en el tocador, quien es el responsable de educar a Eugenia en el desprecio a cualquier clase de principio moral que le impida sumergirse en los senderos del mal. Para esto, le entrega una serie de herramientas filosóficas, históricas y eróticas. 
acude a la banalidad del mal en un nivel estrictamente objetivo que pretende dar a conocer un fenómeno que resultó evidente en el juicio a Eichmann:

Eichmann no era un Yago ni era un Macbeth, y nada pudo estar más lejos de sus intenciones que "resultar un villano", al decir de Ricardo III. Eichmann carecía de motivos, salvo aquellos demostrados por su extraordinaria diligencia en orden a su personal progreso. Y en sí misma, tal diligencia no era criminal; Eichmann hubiera sido absolutamente incapaz de asesinar a su superior, para heredar su cargo. Para expresarlo en palabras llanas, podemos decir que Eichmann, sencillamente, no supo jamás lo que se hacia (Arendt 434).

Aunque Arendt descarta que Eichmann fuera un imbécil, piensa que su irreflexión fue lo que le predispuso a convertirse en el mayor criminal de su tiempo. Para Arendt, la banalidad del mal tiene que ver con no tener conciencia de la maldad y no sentir responsabilidad por las atrocidades cometidas. Eichmann no tenía impulsos genocidas ni un marcado antisemitismo, sin embargo, se limitó a obedecer una ley criminal que conducía a perpetrar delitos contra la humanidad ${ }^{13}$, inauditas atrocidades que las necesidades militares en modo alguno pueden justificar.

Sammer comparte los patrones de conducta empleados por Eichmann en la medida en que concentra sus fuerzas en cumplir una orden que atenta contra la condición humana. Cuando las fuerzas alemanas están en retirada de Europa Oriental, Sammer recibe por error a 500 judíos que debían llegar a Auschwitz. Acorde a los múltiples problemas de la administración nazi, Sammer recibe la orden de 'solucionar el problema'. Así, organiza una brigada con sus funcionarios que se dedica a exterminar a los judíos:

A las cinco de la tarde volvió el jefe de policía y mi secretario [...] Dijeron que todo había salido según lo planeado. Fueron a la antigua curtiduría y salieron del pueblo con dos brigadas de barrenderos $[\ldots]$

13 Los crímenes contra la humanidad irrumpen en la Segunda Guerra Mundial en el momento en que el régimen nazi determina la exterminación de pueblo judío: “[...] con lo que un nuevo crimen, un crimen contra la humanidad - en el sentido de crimen "contra la condición humana' o contra la naturaleza de la humanidad-, hizo su aparición en la historia" (Arendt 406). La "solución final" atenta contra una de las condiciones propias de la humanidad: su diversidad. 
y se dirigieron con paso cansino a la hondonada. Y allí había sucedido lo que tenía que suceder (Bolaño, 2666 952).

Pese a la inicial 'eficacia' del grupo, pronto se encuentra con problemas que ponen de manifiesto la voluntad de Sammer para alcanzar su meta a cualquier precio y su absoluta inconsciencia respecto de las crueldades que está realizando con los judíos. Cuando se le acaba el terreno en la explanada en que estaba arrojando los cadáveres se lanza con nuevos bríos a buscar espacios vírgenes: "Sin embargo al final mi tenacidad obtuvo la victoria. Encontramos un lugar vacío y allí puse a trabajar a todos los hombres. Les dije que cavaran hondo, siempre hacia abajo, más abajo todavía, como si quisiéramos llegar al infierno" (956). Luego de algunos días de 'trabajo' los miembros de su escuadrón se agotan debido a lo que Sammer opta por formar un nuevo grupo integrado por 'niños polacos borrachos', los que continúan con la exterminación de los judíos a cambio de regalías económicas: "Los arengué. Les dije que estaban haciéndolo bien y que sus familias tenían más comida, más posibilidades" (956). Así, Sammer deja entrever la irrupción de un nuevo tipo de criminal que no es ni pervertido ni sádico sino que fue y sigue siendo terroríficamente normal ${ }^{14}$.

El régimen nazi impulsó un patrón de conducta que estaba determinado por un concepto clave para entender el horror del holocausto: la 'despiadada dureza'. Para Arendt la 'despiadada dureza' es la '“[...] simple carencia de bondad, como si nada malo hubiera en quienes estaban dotados de tal cualidad, salvo una lamentable incapacidad de comportarse de acuerdo con las insoportables normas de la caridad cristiana" (Arendt 245). La 'despiadada dureza' es el sustrato valórico de agentes responsables de implementar la 'solución final'. Aunque Carlos Ramírez Hoffman actúa geográfica y temporalmente muy lejos de la Alemania de Hitler, específicamente bajo la dictadura de Pinochet, es dable sostener que éste procede acorde a la 'despiadada dureza', tal como lo demuestra su participación en acciones propias de la barbarie colectiva extrema.

14 Para Arendt, desde el punto de vista de las instituciones jurídicas y de los criterios morales, "[...] esta normalidad resultaba más terrorífica que todas las atrocidades juntas, por cuanto implicaba que este nuevo tipo de delincuente [...] que en realidad merece la calificación de hostis generis humanis, comete sus delitos en circunstancias que casi le impiden saber o intuir que realiza actos de maldad" (Arendt 417). 
Bolaño narra la historia de Ramírez Hoffman en el capítulo final de $L a$ literatura nazi en América ${ }^{15}$, donde presenta a un poeta vanguardista y agente de seguridad de la Fuerza Aérea Chilena que actúa tras el golpe de Estado. Ramírez Hoffman se dedica a eliminar a los partidarios de Salvador Allende, sobre todo, a artistas y poetas, muchos de los cuales eran parte del taller de poesía que el mismo frecuentaba:

Se dirige a la habitación de la tía mientras escucha el motor de un coche que se acerca a la casa, y luego degüella a la tía, no, le clava un cuchillo en el corazón, más limpio, más rápido, le tapa la boca y le entierra el cuchillo en el corazón y después baja y abre la puerta y entran dos hombres en la casa de las estrellas del taller de poesía de Juan Cherniakovski y la jodida noche entra en la casa (179).

Los asesinatos de Magdalena y María Venegas son el inicio de una cadena de crímenes funcionales al régimen militar en cuanto eliminan a sus adversarios políticos. Ahora bien, se trata de algo más que simples homicidios debido a que Ramírez Hoffman hace desaparecer los cuerpos. Para Petter Bamm la desaparición de cuerpos es un 'refinamiento' propio de los gobiernos totalitarios de nuestro siglo, "[...] el que consiste en no permitir que quienes a él se oponen mueran, por sus convicciones, la grande y dramática muerte del mártir [...] los estados totalitarios se limitan a hacer desaparecer a sus enemigos en el silencio del anonimato" (Arendt 351). Ramírez Hoffman se aboca a ocultar las atrocidades de un gobierno criminal. Sin embargo, su trabajo no será perfecto, pues un cuerpo será testigo de su perversión: "Y no hay cadáveres, o sí, hay un cadáver, un cadáver que aparecerá años después en una fosa común, el de Magdalena Venegas, pero únicamente ése, como para probar que Ramírez Hoffman es un hombre y no un dios" (Bolaño, La literatura nazi 179).

Los desgarramientos de la barbarie colectiva extrema se extienden, además, por Nocturno de Chile. El sacerdote Sebastián Urrutia Lacroix rememora las torturas que suceden en la casa de la escritora María Canales ${ }^{16}$,

15 Estrella distante retoma la historia de "Ramírez Hoffman, el Infame". Para Bolaño no es "[...] espejo ni explosión de otras historias sino espejo y explosión de sí misma” (Bolaño, Estrella distante 11).

16 La narración de Urrutia Lacroix cobra más interés al considerar que Bolaño reconstruye un episodio de la vida real. Bolaño retoma un fragmento de la vida de Mariana Callejas y Michael Townley -colaboradores del régimen militar- que ya había narrado en la crónica "El 
específicamente, las sesiones de electroshocks que sufren los presos políticos. En Chile, las sesiones de electroshocks fueron rebautizadas como 'parrilla', método de tortura que consiste en la aplicación de descargas eléctricas en la totalidad del cuerpo o bien en zonas específicas, particularmente, en las regiones genitales.

Urrutia Lacroix revela una de las uniones más feroces del arte y del crimen en la literatura hispanoamericana: las reuniones en casa de María Canales y James Thompson. Mientras Canales es una escritora en ciernes, Thompson es un torturador de la DINA. De esta forma, se da la curiosidad que mientras Canales organiza veladas artísticas con parte de la intelectualidad chilena de la época, Thompson realiza sesiones de interrogación en el sótano de su casa: "Los subversivos pasaban por los sótanos de Jimmy, en donde éste los interrogaba, les extraía toda la información posible y luego los remitía a otros centros de detención. En su casa, por regla general, no se mataba a nadie. Sólo se interrogaba aunque algunos murieron" (Bolaño, Nocturno de Chile 141). Crimen y arte habitan un mismo espacio en la casa, separados tan solo por algunas habitaciones que, en definitiva, hacen imposible que no acaben tocándose la punta de la pluma con el filo de la espada. El contacto sucede cuando un escritor, sumido en el aletargamiento del licor, se pierde por los recovecos de la casa hasta llegar a una habitación en penumbras:

[...] y abrió la puerta y vio al hombre atado a una cama metálica, los ojos vendados, y supo que el hombre estaba vivo porque lo oyó respirar, aunque su estado físico no era bueno, pues pese a la luz deficiente vio sus heridas, sus supuraciones, como eczemas, pero no eran eczemas, las partes maltratadas de su anatomía, las partes hinchadas, como si tuviera más de un hueso roto, pero respiraba, en modo alguno parecía alguien a punto de morir, y luego [...] cerró delicadamente la puerta, sin hacer ruido, y empezó a buscar el camino de vuelta a la sala (140).

Bolaño retrata una de las técnicas más utilizadas para torturar a los opositores de la dictadura y una de las más efectivas para controlar a la ciudadanía. Lo anterior responde a que los cuerpos de los detenidos son un testimonio y,

pasillo sin salida aparente", donde señala: "Y para terminar, una historia verídica. Lo repito: esto no es un cuento, es real, ocurrió en Chile durante la dictadura de Pinochet y más o menos todo el mundo (ese "todo el mundo" pequeño y lejano que es Chile) lo sabe" (Bolaño, Entre paréntesis 77). Luego narra la misma historia contada en Nocturno de Chile. 
sobre todo, una advertencia de las consecuencias que implica resistir a las políticas impuestas por el régimen.

\section{TORMENTA DE MIERDA ${ }^{17}$}

Los cursos de acción del mal acaban en la degradación del ser humano. Para Sichère enunciar el mal equivale a señalar el momento de horror que está en cada hombre, quien se define como hombre cuando no consiente la abyección "[...] no hay hombres buenos y hombres malos, verdugos de nacimiento y víctimas predestinadas, sino que cada hombre lleva en sí mismo lo peor como una posibilidad atroz" (Sichère 206). Klaus Haas, sospechoso de los asesinatos de mujeres de Santa Teresa, representa el descenso en la abyección. Haas muestra cierta propensión hacia el mal desde su juventud. Involucrado en pequeños robos e intentos de abuso sexual decide viajar a América. En México mantiene contacto con una de las mujeres asesinadas en Santa Teresa, lo que lleva a la policía a inculparlo por los crímenes. Aunque Bolaño no da certezas respecto de la culpabilidad de Haas, conocemos los hechos en que se ve envuelto en la cárcel. Luego de sortear un intento de violación, Haas opta por sumirse en la abyección:

Haas le arrebató el punzón al Guajolote y le dijo al Anillo que se pusiera en cuatro patas. Si no tiemblas, pendejo, nada te pasará. Si tiemblas o tienes miedo, vas a tener dos agujeros para cagar. El Anillo se quitó la toalla y se puso en el suelo a cuatro patas [...] Luego se arrodilló detrás del Anillo, le susurró a éste que se abriera bien de piernas y le introdujo lentamente el punzón hasta el mango (Bolaño, 2666 607).

La abyección se puede mirar, también, como la violencia que ejercen los sujetos del mal con el fin de ensuciar y humillar al otro. Bajo esta perspectiva, están las nociones de Julia Kristeva, quien entiende la abyección como aquella turbiedad que provoca el rechazo pero a la vez el deseo y que lacera y pervierte a las personas que se hunden en sus arenas pútridas. Para Kristeva, lo abyecto es la amenaza real que convoca y que acaba por sumergirnos.

17 Tormenta de mierda era el título que, originalmente, iba a tener Nocturno de Chile. Jorge Herralde - editor de Anagrama- y Juan Villoro convencieron a Bolaño de cambiar el nombre de la novela. 
Kristeva cree que la abyección no se trata tanto de la ausencia de limpieza o de salud sino de aquello que perturba una identidad, un sistema y un orden. Kristeva agrega, en este sentido, que la abyección no respeta los límites ni los lugares ni las reglas, "[...] es inmoral, tenebrosa, amiga de rodeos, turbia: un terror que disimula, un odio que sonríe, una pasión por un cuerpo cuando lo comercia en lugar de abrasarlo, un deudor que estafa, un amigo que nos clava un puñal por la espalda" (Kristeva 11).

Bolaño trata de manera permanente esta clase de abyección en sus novelas. En Los detectives salvajes se encuentra el proxeneta Alberto, cuya abyección no solo pasa por comerciar con cuerpos femeninos sino por su tendencia a ultrajar -aún más- a quienes lo rodean. Lo anterior se evidencia en el 'reventón de mamadas' en que degrada públicamente a la campeona:

\begin{abstract}
Alberto la cogió de las orejas y se la metió entera [...] En los primeros segundos la ruca pareció que aguantaba, pero luego se atragantó y empezó a ahogarse [...] La ruca empezó a golpear a Alberto, a intentar separarse de él, y Alberto empezó a reírse y a decirle so, yegua, so, yegua, como si estuviera montando una yegua brava (50).
\end{abstract}

El rey de los putos de la Colonia Guerrero es uno de los mayores representantes de la abyección en la narrativa bolañiana. No solo porque controla la prostitución masculina en parte del DF sino porque es un personaje que tiende a llevar la degradación hasta el extremo: creando esclavos. En Amuleto, Auxilio Lacouture entrega los detalles del enfrentamiento de Ernesto San Epifanio y Arturo Belano contra el rufián mexicano:

Y el Rey, según Ernesto San Epifanio, había comprado su cuerpo y ahora él le pertenecía en cuerpo y alma [...] y si es que no accedía a sus requisitorias la justicia y el rencor del Rey caerían contra él [...]Y después dijo que $[\ldots]$ si las cosas seguían así tendría que convertirse en el esclavo del rey de los putos de la colonia Guerrero (74).

El rey de los putos erige su poder sobre tres elementos. En primer lugar, en un código de conducta que rige de manera implacable a quienes tienen la osadía o la estupidez de entablar algún tipo de relación con el proxeneta: "El Rey evocó dos noches en las que Ernesto se había sumergido voluntariamente y habló de contraer obligaciones, las obligaciones que todo acto, por gratuito o accidental que sea, conlleva" (81-82). Pues bien, las dos noches que San Epifanio pasó en la cama del rey son suficientes en su 'normativa' para que San Epifanio pase a convertirse en su esclavo. En segundo lugar, el rey de 
los putos ejerce su dominio a través del miedo, el que tiene que ver con la posibilidad de destrozar a quienes infrinjan sus leyes. En tercer lugar, tiene que ver con la violencia que es capaz de ejercer contra sus víctimas. El rey de los putos no practica su poder solo a través del discurso, Juan de Dios Montes - uno de sus esclavos-constituye un signo de la perturbadora violencia ejercida por el criminal:

En las penumbras que envolvían la cama, un tercer hombre nos vigilaba y nos escuchaba moviendo la cabeza. Yo lo primero que pensé fue que ese hombre no estaba bien. Al principio fue lo único que me dio miedo, pero conforme pasaron los minutos el temor se transformó en conmiseración: pensé que el hombre que estaba semirrecostado en la cama $[\ldots]$ no podía sino ser alguien enfermo, tal vez un subnormal. (81)

Más que los estragos de la abyección física, Juan de Dios Montes constituye un paradigma de la degradación moral en tanto que acepta su sumisión: "Tu eres mi puto esclavo, dijo interrumpiéndolo el Rey. Yo soy tu puto esclavo, dijo el hombre [...] que estaba en el fondo de la habitación" (82). Juan es víctima de la turbiedad que hiere a los seres humanos hasta llevarlos a la más infamante degradación.

\section{AMENAZAS FANTASMAS}

La "Estética de la Aniquilación" encuentra su vertiente más sutil en la presencia de lo siniestro en la narrativa de Bolaño. Principalmente porque Bolaño focaliza su atención mucho más en la amenaza latente que representa la aniquilación que en la aniquilación misma. Así, Bolaño se aboca a desentrañar el horror que enfrentan diversos personajes ante la posibilidad de ser devastados. Sigmund Freud sostiene que lo siniestro es un concepto: “[...] próximo a lo espantable, angustiante, espeluznante" (Freud 344). Freud sustenta su visión de lo siniestro a partir de una nota de Schelling, la que amplía, precisa y define el contenido de la noción de lo siniestro como: "[...] todo lo que debía haber quedado oculto, secreto, pero que se ha manifestado" (Freud 344).

Monsieur Pain constituye uno de los textos más interesantes en cuanto al tratamiento de lo siniestro del catálogo bolañiano, puesto que el mal emerge no como una acción tendiente a destruir al otro sino como una fuerza orientada 
a neutralizar la acción de quienes podrían intervenir para ayudar al otro. De esta forma, los diversos actores que intervienen en la novela apuntan a impedir que el mesmerista Pierre Pain cure el hipo del sudamericano Vallejo, quien deambula hacia una muerte inexorable con el tratamiento médico que recibe en una clínica de París.

Pain debe enfrentar la manifestación de aquellas fuerzas que tienden a detener su deseo de ayudar al poeta y que son representadas, en primer lugar, por las oscuras figuras de dos españoles que "[...] llevaban gabardinas oscuras y sombreros de ala ancha que [...] velaban sus rostros [...] Policías, pensé, sólo ellos conservan esa forma de mirar, herencia de cazadores y de bosques umbríos" (Bolaño, Monsieur Pain 15-16). Precisamente son éstos quienes tientan a Pain para que no ayude a Vallejo argumentando que su marginación contribuiría al bienestar de la humanidad: "El bien común [...] una bonita definición, el bien suyo y el bien de todos... La armonía... El equilibrio... Las esferas estabilizadas [...] Las sonrisas" (16). En nombre de ese 'bien común' se mueven desde elementos triviales, como las órdenes que esgrime una enfermera para impedir que Pain ingrese a la clínica donde se hallaba Vallejo, a hechos que superan la cotidianeidad y que se conectan con lo que Sichère denomina pesadilla, es decir, la exhibición cruda y desnuda de una realidad intolerable. En este sentido, se halla el incidente en que Pain se ve envuelto cuando logra finalmente entrar a la clínica:

[...] vi aquello al final del pasillo, como si todo el tiempo hubiera estado allí esperándome. Era apenas una silueta confusa, un cuerpo sin brazos, una pesadilla catapultada de golpe desde la infancia. Inspiraba más piedad que miedo, pero su presencia era insoportable [...] Mis manos temblaban. Intuí que la silueta también estaba temblando. Di media vuelta y me eché a correr (145).

La suma de incidentes hace que Pain comience a deducir que se halla en el epicentro de fuerzas que lo superan y en el que cada personaje tiene un papel que desempeñar. Pero ¿qué se encuentra detrás del deseo de que muera un poeta sudamericano? Resulta imposible llegar a conocer con exactitud esa respuesta con los elementos que entrega el texto. Sin embargo, los argumentos esgrimidos por los españoles hacen pensar que la restauración de la armonía tiene que ver con poner fin a la voluntad rupturista de Vallejo, la que más que apuntar a su vinculación con los movimientos de izquierda tiene que ver con sus lineamientos poéticos. El curso de los acontecimientos indica que todo se trata de un ritual macabro en el que Vallejo es una ofrenda. En esta 
línea, se encuentra la reflexión del mesmerista Terzeff sobre la muerte de Pierre Curie y que permiten establecer una analogía con el desenlace fatal de Vallejo. Terzeff creía que Curie no había perecido producto de un accidente sino que había sido asesinado: "En claro saqué que mataron a Curie no por lo que hacía [...] y que su muerte cumplía [...] una función ritual” (137).

Vallejo está en una situación similar a la de Curie. Aunque padece una enfermedad que justifica su deceso, la deficitaria atención médica que recibe y los intentos por impedir que Pain atienda al poeta hacen pensar que detrás de la condición de Vallejo se halla algo más. Pain ratifica esa conclusión: "Pensé: hay un inocente de por medio. Pensé: el sudamericano va a pagar por todos" (128).

\section{EL SILENCIO DE LOS CORDEROS}

La criminalidad extrema es una de las manifestaciones del mal en el siglo XX, la que, a diferencia de la delincuencia corriente, constituye una infracción bárbara que suscita una emoción particular. Para Sichère, el crimen extremo exhibe "[...] de manera desnuda y violenta el horror y, en cierto sentido, actualiza lo que bien podemos continuar llamando el 'misterio de iniquidad" (212). James Ellroy es uno de los narradores que aborda con mayor profundidad la criminalidad extrema, considerándola como la desunión colectiva alojada en el corazón de la sociedad. Sichère sostiene que la obra de Ellroy no se contenta con describir el fenómeno del mal sino que analiza los mecanismos sociales que sustentan la perversión. Los puntos centrales de la literatura de Ellroy son la figura del serial killer -en el que convergen la subjetividad criminal y el horror sexual-y la presencia de un momento de horror que es el centro de expansión del mal.

Las novelas de Bolaño dialogan con la criminalidad extrema en la medida en que exhiben quebrantamientos del orden en distintas sociedades occidentales. A diferencia de la construcción narrativa de Ellroy, que levanta sus textos sobre un solo crimen, Bolaño tiende a erigir sus novelas sobre múltiples horrores que generan una sensación de totalidad. Si hay una analogía permanente entre las novelas de Ellroy y Bolaño, ésta es la presencia del serial killer, símbolo de una inhumanidad radical que atraviesa varias de sus piezas literarias. 2666 es una novela pródiga en serial killers. No solo por los responsables de los asesinatos de mujeres. También por la presencia de una amplia gama de psicópatas en una urbe destrozada por la miseria y la 
corrupción. En la cárcel de Santa Teresa encontramos a Ayala o el hígado negro de la frontera, cuyo apodo proviene de su 'peculiar' manera de trabajar como 'coyote':

Entre las muchas muertes que debía Ayala, estaban las de ocho emigrantes a los que pasó a Arizona a bordo de una Pick-up. Al cabo de tres días de estar desaparecido Ayala volvió a Santa Teresa, pero [...] de los emigrantes nada se supo hasta que los gringos encontraron $[\ldots]$ el vehiculo, con sangre por todos los sitios, como si Ayala, antes de volver sobre sus pasos, se hubiera dedicado a trocear los cuerpos [...] ¿Qué hizo Ayala con los cadáveres? Según el Tequila, se los comió, así era de grande su locura y su maldad (652).

Para terminar, hablaré de Amberes, novela de atmósferas opresivas en que se debaten ladrones, asesinos, policías y mujeres fatales, dejando en el crimen $\mathrm{y}$, sobre todo, en su singularidad extrema el epicentro del mal. Bolaño sitúa como uno de los núcleos del relato un episodio que constituye el centro de expansión del mal: "A simple vista uno podía notar que no había muerto de un ataque cardiaco. Estaba bocabajo y en la espalda, sobre el suéter marrón, se apreciaban varios agujeros de bala" (Bolaño, Amberes 10). El asesinato resulta interesante en la medida en que no solo exhibe de manera cruda la violencia sino que al velar la identidad del homicida evidencia uno de los elementos fundamentales de la maldad bolañiana: el debate entre causalidad y casualidad. Así, resulta capital la reflexión del detective Abel Romero sobre el origen del mal en Los detectives salvajes: "Si es causal, podemos luchar contra él, es difícil de derrotar pero hay una posibilidad, más o menos como dos boxeadores del mismo peso. Si es casual, por el contrario, estamos jodidos" (Bolaño, Los detectives salvajes 397). Bolaño responde a esa compleja pregunta en Estrella distante. Graham Greenwood postula la teoría del mal absoluto, "[...] en su particular teología, el infierno era un entramado o una cadena de casualidades. Explicaba los asesinatos en serie como una "explosión del azar". Explicaba las muertes de los inocentes [...] como el lenguaje de ese azar liberado. La casa del diablo, decía, era la Ventura" (Bolaño, Estrella distante 110).

Cuando Amberes revela el siniestro crimen de un hombre cuyo asesino carece de motivos, me parece que el narrador chileno opta por la casualidad. No creo advertir, por lo demás, causas que expliquen el asesinato de Carmen en La pista de hielo. Y qué podemos decir de Carlos Wieder. Sabemos que sus crímenes responden a una política de Estado, pero desconocemos qué razones llevan a Wieder a transformarse en un infame. 
El origen del mal me recuerda un tropo permanente en los textos de Bolaño: la tormenta. Las novelas bolañianas son azotadas por tormentas físicas y psíquicas que remueven las ciudades y las estructuras mentales de los personajes. Así, siempre se está desplegando una 'tormenta de mierda' que tiende a destruir a los seres humanos. Y esa tormenta no es sino la explosión del azar que nos recuerda que el ser humano está obligado a enfrentar la oscuridad. Benard Sichère habla del desencadenarse de la tempestad, que significa la desaparición de los puntos de referencia humanos; me parece que en las novelas de Bolaño ocurre algo similar, los lectores que penetran sus páginas pueden palpar la explosión de la tormenta que aniquila, anula y arrastra a mujeres y hombres a infiernos diseñados a su medida.

La presencia de la tormenta en la narrativa de Bolaño evoca la mirada aterrorizada del ángel de la Historia ${ }^{18}$. Walter Benjamin construye una imagen interesante no solo por el surgimiento del mal en el paraíso, más aún cuando la divinidad tiene escasa o aun nula presencia en la narrativa de Bolaño, sino por la continuidad que tiene la tormenta, gestándose desde el inicio como una fuerza que apila escombros sobre escombros: la aniquilación. Desde Argos a la Santa Teresa del siglo XXI, pasando por el Berlín de la Segunda Guerra Mundial y el Santiago de Chile de 1973, la tormenta desencadena las fuerzas destructivas sobre la humanidad en las novelas de Roberto Bolaño, dejando a su paso un reguero de muerte y desolación sobre el que, en muchas ocasiones, se esconden las transformaciones que dan paso al 'progreso' de la humanidad.

La narrativa de Bolaño está cruzada por variadas manifestaciones del mal, sin embargo, creo que todas estas facetas no hacen sino reflejar ese mal único y radical que anida en el corazón del hombre. Así, toma forma la "Estética de la Aniquilación", vale decir, la narración de las múltiples formas de destruir a los seres humanos a fin de exponer la orgía de aniquilación en la que se ha basado parte importante de la historia del hombre. No hay un intento por exponer la belleza ni mucho menos el sentido del humor, debido

18 Walter Benjamin establece como sus ojos abiertos ven: “[...] una sola catástrofe, que incesantemente acumula escombros sobre escombros y los arroja a sus pies. El ángel quisiera quedarse, despertar a los muertos y unir lo destrozado. Pero desde el Paraíso sopla una tormenta que se ha enredado en sus alas con tanta fuerza que el ángel no puede cerrarlas ya. Esa tormenta lo empuja incesantemente hacia el futuro, al que da la espalda, mientras el montón de escombros que tiene delante crece hasta el cielo. Esa tormenta es lo que llamamos progreso" (Benjamin 273). 
a que Bolaño muestra la aniquilación para dejar constancia, simplemente, de la aniquilación. ¿Qué hay entonces detrás de tanto mal? Hay un viaje vertical. El deseo de penetrar en las entrañas de la oscuridad para hallar algo de luz. "Aprendan del fuego", dice uno de los versos que Ramírez Hoffman escribe en el cielo de Santiago. Creo que ahí está la clave de todo. Bolaño parece querer descubrir en la "Estética de la Aniquilación" una advertencia sobre el fin de todos los humanos. Me parece un grito agónico que advierte que es imposible escapar a los instintos de muerte, porque las bombas de la ventura tarde o temprano alcanzarán al ser humano pero, en ese breve espacio de tiempo, los hombres tienen la posibilidad de penetrar y alcanzar lo "mágico", aquello que hace que la vida sea algo más que una cifra y una pesadilla. Asimismo, no se puede soslayar que Bolaño expone el mal con el fin de impugnarlo, tal como comenta Juan Villoro en "La batalla futura": "Conocer los circuitos en que se mueve el horror, distinguir la metodología del mal, son formas de comenzar a refutarlos" (Braithwaite 13). Bolaño narra el horror como una forma de contradecir los alcances del mal, exponiendo los mecanismos que mueven a las fuerzas de la aniquilación. No creo que haya un intento de Bolaño por exorcizar el mal. Bolaño tiene claros los alcances y los límites de la literatura. Sin embargo, existe un deseo de subrayar aquellos aspectos mágicos como una forma de que los seres humanos exploten y disfruten aquellos aspectos que reafirman la vida y el placer. Así, Bolaño erige un pequeño paraíso que ha de situarse en medio del enorme averno que constituye la "Estética de la Aniquilación".

\section{BIBLIOGRAFÍA}

Arendt, Hannah. Eichmann en Jerusalén, Un estudio sobre la banalidad del mal. Barcelona: Lumen, 2000.

Bataille, Georges. La literatura y el mal. Madrid: Taurus Ediciones, 1959.

Baudrillard, Jean. La transparencia del mal: ensayo sobre los fenómenos extremos. Barcelona: Anagrama, 2001.

Benjamin, Walter. Obras. Trad. Alfredo Brotons Muñoz. Madrid: Abada Editores, 2006.

Bolaño, Roberto. Amberes. Barcelona: Anagrama, 2002. Amuleto. Barcelona: Anagrama, 2002. Entre paréntesis. Barcelona: Anagrama, 2004 Estrella distante. Barcelona: Anagrama, 1996. La pista de hielo. Barcelona: Seix Barral, 2003. La literatura nazi en América. Barcelona: Seix Barral, 1996. 
Los detectives salvajes. Barcelona: Anagrama, Compactos 232, 2002.

Monsieur Pain. Barcelona: Anagrama, 1999.

Nocturno de Chile. Barcelona: Anagrama, 2000.

Una novelita lumpen. Barcelona: Random House Mondadori, 2002.

2666. Barcelona: Anagrama, 2004.

Bolaño, Roberto y Antoni García Porta. Consejos de un discípulo de Morrison a un fanático de Joyce. Barcelona: Anthropos, Ed. del Hombre, 1984.

Braithwaite, Andrés ed. Bolaño por sí mismo. Entrevistas escogidas. Santiago: Ediciones Universidad Diego Portales, 2006.

Borges, Jorge Luis. Discusión. Buenos Aires: Emecé Editores, 1964.

Brunner, Jose Joaquin. Globalización cultural y postmodernidad. Santiago: Fondo de Cultura Económica, 1998.

Comisión Nacional sobre Prisión Política y Tortura. Informe de la Comisión Nacional sobre Prisión Política y Tortura. Santiago: La Nación S.A., 2004.

Deleuze, Gilles. "Coldness and cruelty". Masochism. New York: Zone Brooks, 1989.

Espinoza, Patricia. "Estudio preliminar". Territorios en fuga. Estudios críticos sobre la obra de Roberto Bolaño. Santiago: Frasia editores (2003): 13-32.

Freud, Sigmund, Lo siniestro. Obras completas. Santiago: Pax, 1935.

González, Daniuska: "Roberto Bolaño, El silencio del mal”. Revista Quimera 241 (2004): 28-31.

Jung, Carl. Arquetipos e inconsciente colectivo. Barcelona: Paidós, 1970.

Kristeva, Julia. Poderes de la perversión. Buenos Aires: Siglo XXI Editores, S.A., 1988.

Manzoni, Celina. "Biografías mínimas/ínfimas y el equívoco del mal”. Ed. Manzoni, Celina: Roberto Bolaño la escritura como tauromaquia. Buenos Aires: Ediciones Corregidor, 2002.

Pellegrini, Aldo. "Fundamentos para una Estética de la Destrucción”. http://pompeyoaudivert. blogspot.com/2007/07/fundamentos-para-una-esttica-de-la.html (13/8/2006).

Rojo, Grínor. "Bolaño y Chile". Anales de la Literatura Chilena 5 (2004): 201-212.

Sebald, W.G. Sobre la historia natural de la destrucción. Trad. Miguel Sáenz. Barcelona: Anagrama, 2005.

Sichère, Bernard. Historias del mal. Barcelona: Gedisa, 1996. 